\title{
Immunobiology of gestational zinc deficiency
}

\author{
Nele Wellinghausen \\ Department of Medical Microbiology and Hygiene, University of Ulm, Robert-Koch-Str. 8, D-89081 Ulm, Germany
}

\begin{abstract}
The trace element zinc is an essential micronutrient for the proper functioning of the immune system. Zinc deficiency leads to impaired function of the unspecific and specific immune response and consequently to an increased susceptibility to bacterial, viral and fungal infections. Immunological defects are not only seen in pronounced but even in marginal and moderate zinc deficiency. Lack of zinc is especially harmful for the development of the immune system, which stresses the importance of a balanced zinc level during pregnancy. However, gestational zinc deficiency due to an imbalance between intake and increased requirements is a common problem world-wide. In animals, gestational zinc deficiency results in reduced thymic and spleen size and depressed active and passive immunity in the infant. For example, depressed immunoglobulin levels, altered antibody repertoire, reduced proliferative response of lymphocytes and diminished neutrophil functions have been reported. Interestingly, immune defects caused by prenatal zinc deficiency, such as depressed antibody levels and lymphocyte proliferation, may even persist in subsequent generations and are not reversible by postnatal zinc administration. Since gestational zinc deficiency is a common problem throughout all cultures and socioeconomic levels, it might have immense consequences for the health status of the population. Based on a summary of the immunobiology of zinc, this article reviews the significance of zinc deficiency during pregnancy and the effect of gestational zinc deficiency on passive and active immunity in the infant. It provides a rational basis for both immunological laboratory investigations and field studies, such as large community-based zinc supplementation trials in pregnant women.
\end{abstract}

Zinc deficiency: Pregnancy: Zinc supplementation: Immunology

\section{Introduction}

The significance of zinc for human nutrition was discovered some decades ago (Prasad, 1991) but only now are the mechanisms responsible for the pathophysiology of zinc deficiency becoming clear. The observed association between increased susceptibility to infectious diseases and nutritional zinc deficiency led researchers to hypothesize that the trace element zinc must be important for immunity. The most extreme form of zinc deficiency can be studied in the zinc-specific malabsorption syndrome acrodermatitis enteropathica, a rare autosomal recessive inheritable disease (Neldner \& Hambidge, 1975). The immunological significance of zinc, however, also becomes clear in several more frequent conditions, particularly in malnutrition. Lack of zinc is especially harmful to the development of the immune system when it occurs during critical periods of ontogeny, which stresses the importance of a balanced zinc level during pregnancy. However, gestational zinc deficiency due to imbalances between intake and increased requirements is a common problem world-wide. In this article, the significance of zinc deficiency for immune function will be reviewed. Special attention will be drawn to the role of mild and moderate zinc deficiency, the significance of zinc deficiency during pregnancy and the influence of gestational zinc deficiency on passive and active immunity in the infant.

\section{Zinc requirements}

Zinc deficiency in humans is mainly due to a lack of bioavailable zinc in the diet, general malnutrition or malabsorption (Good, 1981; Prasad, 1995). Nutritional zinc requirements are difficult to determine since many dietary factors affect the bioavailability of zinc, and physiological requirements of zinc vary greatly between different age groups. However, recommended daily allowances (RDA by the US National Research Council) of $5 \mathrm{mg}$ zinc for infants (i.e. children up to one year of age), $10 \mathrm{mg}$ for children aged 1-14 years, $12 \mathrm{mg}$ for adolescents and nonpregnant and nonlactating females, and $15 \mathrm{mg}$ for pregnant and lactating women and male adults appear reasonable to achieve a normal plasma zinc level of 11-18 $\mu \mathrm{M}$ (National Research Council, 1989). In a recent survey, the Third US National Health and Nutrition Examination Survey, it was shown that these age- and sex-specific RDAs are achieved in the diet of 
Table 1. Immunological consequences of zinc deficiency

\begin{tabular}{ll}
\hline Effects on specific immunity & \multicolumn{1}{c}{ Effects on innate immunity } \\
\hline $\begin{array}{l}\text { Increased involution of the thymus: } \\
\text { - decreased thymocyte count in the thymus }\end{array}$ & Decreased natural killer cell activity \\
- decreased serum level of thymulin & \\
T-cells: & Decreased macrophage functions: \\
- diminished peripheral T-cell count & $\bullet$ phagocytosis \\
- impaired delayed hypersensitivity & $\bullet$ intracellular killing \\
- decreased proliferative response to PHA & \\
- decreased activity of cytotoxic T-cells & \\
- decreased activity of helper T-cells & \\
B-cells: & Decreased neutrophil functions: \\
- decreased antibody production & $\bullet$ chemotaxis \\
& $\bullet$ oxygen burst \\
\hline
\end{tabular}

approximately $55 \%$ of the US population (Briefel et al. 2000). The US National Research Council RDAs are based on a dietary availability of zinc of approximately $20 \%$ when compared to the recommendations of the World Health Organization (National Research Council, 1989; Walsh et al. 1994). If dietary availability of zinc is only $10 \%$, however, as is the case for many human populations, especially in developing countries, the nutritional requirements of zinc might be much higher. Despite our profound knowledge about the zinc intake in the population we still do not know the exact requirements of this micronutrient and there is still controversy whether zinc serum level is the adequate parameter of zinc status. Nevertheless, due to its easy accessibility and the existence of a broad range of studies determination of zinc serum level as parameter of zinc status seems to be appropriately applicable.

\section{Immunological significance of zinc}

The immune system is influenced by zinc on various levels. On the one hand, zinc specifically alters immune functions and, on the other, the immune system which is a highly proliferative 'organ' is influenced by zinc-dependent proteins involved in general cellular functions, i.e. replication, transcription and signal transduction (Valle \& Falchuk, 1993). All cell subsets of the immune response are affected by zinc (Table 1). Decreased zinc levels impair natural killer cell activity, phagocytosis by macrophages and neutrophils, and certain functions like chemotaxis and the oxidative burst (Keen \& Gershwin, 1990). However, zinc is important even for the maturation and functioning of T-cells, since zinc is an essential cofactor for the thymus hormone thymulin (Hadden, 1992). This hormone has intrathymic and peripheral immunoregulatory properties and is necessary for an intact thymus (Bach, 1981; Wellinghausen et al. 1997a). Zinc deficiency thus leads to thymic atrophy. Zinc also affects mature T-cells. It induces the expression of the high-affinity receptor for interleukin-2 and zinc deficiency is associated with decreased T-cell proliferation after mitogen stimulation (Dowd et al. 1986; Kruse-Jarres, 1989). Antibody production of B-cells is also dependent on zinc. Interestingly, impaired antibody production can be restored through addition of thymic cells thus suggesting a T-cell dependent defect (Crea et al. 1990). Furthermore, binding of zinc to immunoglobulins with as yet unclear functional relevance has been shown (Prasad \& Oberleas, 1970). Overall, the clinical consequence of zinc deficiency is an impaired defence against bacterial, viral and fungal infections.

\section{Mild and moderate zinc deficiency}

Not only severe but even moderate and marginal zinc deficiency, which is by far more common than severe deficiency, has a profound effect on immune response since the sensitivity of immune cells to an altered zinc level varies. For instance, in marginal zinc deficiency in mice and humans, thymus size, peripheral blood lymphoid cell counts and antibody levels are suppressed (Shankar \& Prasad, 1998). Interestingly, reduction in thymus size is seen mainly in the cortex, the zone where the development of T-cells takes place (Shankar \& Prasad, 1998). Therefore, the importance of zinc deficiency for the development of the immune response is obvious. The relevance of moderate and marginal zinc deficiency is further stressed by the fact that different functions of a cell are sensitive to zinc deficiency to a variable degree. For instance, intracellular killing by macrophages is much more sensitive to zinc deficiency than interaction with T-cells and phagocytosis, implying a decreased resistence to intracellular pathogens even in marginal zinc deficiency (Shankar \& Prasad, 1998). As a clinical consequence, patients with mild to moderate zinc deficiency may be prone to infections in which macrophage killing is a central effector, such as malaria or tuberculosis.

\section{Zinc status in pregnancy}

During pregnancy, zinc requirements are markedly increased and a meta-analysis of various epidemiological studies investigating the zinc intake by pregnant women estimates an inadequate zinc intake in up to $80 \%$ of cases (Caulfield et al. 1998). Although this estimate appears quite high, it is based on a recommended daily allowance of only $11.5 \pm 1.75 \mathrm{mg}$ zinc per day (Caulfield et al. 1998). Nevertheless, data on zinc intakes are conflicting and a very recent US National Survey found adequate zinc intake in less than $60 \%$ of pregnant women based on a total zinc 
Table 2. Immunological consequences of gestational zinc deficiency for the neonate

\begin{tabular}{ll}
\hline $\begin{array}{l}\text { Consequences for } \\
\text { first-generation offspring } \\
\text { (mice and rhesus monkeys) }\end{array}$ & \multicolumn{1}{c}{$\begin{array}{c}\text { Consequences for } \\
\text { subsequent generations } \\
\text { (mice) }\end{array}$} \\
\hline $\begin{array}{l}\text { Lymphoid organs: } \\
\text { - reduction of thymus and spleen size }\end{array}$ & - \\
$\begin{array}{l}\text { B-cells: } \\
\text { - hypogammaglobulinaemia: } \\
\text { persistent IgM deficiency } \\
\text { transient IgA and IgG }\end{array}$ deficiency & $\begin{array}{l}\text { B-cells: } \\
\text { altered antibody repertoire }\end{array}$ \\
$\begin{array}{l}\text { T-cells: } \\
\text { - impaired proliferative response }\end{array}$ \\
$\begin{array}{l}\text { Depressed neutrophil function: } \\
\text { - chemotaxis }\end{array}$ \\
$\bullet$ phagocytosis
\end{tabular}

intake at or above $77 \%$ of the 1989 RDA (Briefel et al. 2000). Assessment of zinc intake may be complicated for instance by individual, regional and changing food habits. While severe zinc deficiency, based on a distinctly diminished zinc serum level, is relatively rare, mild to moderate zinc deficiency is widespread and not restricted to women of low socioeconomic status. Physiologically, the zinc serum level declines during pregnancy, mainly due to hemodilution and decreased albumin levels (Bedwal \& Bahuguna, 1994; Jameson, 1993). While 10.5 $\mu \mathrm{M}$ is considered as the lower limit of serum zinc during the first and second trimester, the zinc level physiologically declines down to $9.5 \mu \mathrm{M}$ in the third trimester (Jameson, 1993). Insufficient intake further aggravates the physiological drop of zinc. Furthermore, not only serum zinc but also zinc content in peripheral blood leucocytes has been observed to decrease from the second trimester of normal pregnancy (Valdes-Ramos, 1992) and correlates with fetus leucocyte levels (Favier, 1992). Intestinal absorption is not increased during pregnancy and thus the additional zinc requirements by fetal and placental tissues have to be covered from increased intake or from maternal tissues (Favier, 1992)

Zinc deficiency during pregnancy provokes similar symptoms and increased susceptibility to infections as does zinc deficiency in non-pregnant adults. However, infections might be more prolonged or severe due to physiological pregnancy-related metabolic and hormonal changes (Favier, 1992). Zinc supplementation at the end of pregnancy has only a weak effect on mothers' zinc status but, if administered during the first trimester, serum zinc increases after supplementation (Favier, 1992). Therefore, an early recognition and correction of zinc deficiency during pregnancy are necessary. In a recent study, Caulfield et al. showed, that continuous daily zinc supplementation in pregnant women, started at week 10-24 of gestation and continued until 4 weeks after delivery, leads to increased serum zinc concentrations in the mother and increased cord zinc concentration in the neonate (Caulfield et al. $1999 a)$.

\section{Effects of gestational zinc deficiency on the immunity of the infant}

Zinc deficiency during pregnancy affects not only the mother but it also has immunological consequences for the fetus. Various immune defects have been reported in animal studies. In mice and rhesus monkeys suffering from prenatal zinc deficiency, a reduction in lymphoid organ size, like thymus and spleen, leading to cellular immune defects has been found (Beach et al. 1982a). One of the earliest and clinically most relevant signs of maternal zinc deficiency are low levels of natural immunoglobulins including a persistent defect in IgM and transiently diminished levels of $\operatorname{IgA}$ and $\operatorname{IgG}_{2}$ in the neonate (Table 2; Favier, 1992). Diminished placental transport of immunoglobulins has been proposed as a possible explanation (Shankar \& Prasad, 1998). However, not only is the total amount of antibodies diminished; even the repertoire of antigens recognized by these antibodies is depressed. Interestingly, this effect is even seen in mild or transient zinc deficiency during pregnancy (Shankar \& Prasad, 1998). Certain developmental steps responsible for B-cell receptor repertoire maturation thus seem to be dependent on zinc. Concerning T-cell function, impaired proliferative response to mitogen has been observed in the offspring of zinc-deficient animals (Keen \& Gershwin, 1990). In mice, prenatal zinc deficiency has led to an inability to form rosettes after immunization (Beach et al. 1983). In addition to a negative impact on the specific immune responses, depression of innate immune mechanisms like chemotaxis and phagocytosis of neutrophils has also been found (Shankar \& Prasad, 1998). Furthermore, prenatal zinc deficiency leads to disturbed postnatal metabolism of the major intracellular zinc binding protein, metallothionein, which has a profound effect on zinc homoeostasis (Vruwink et al. 1988).

Interestingly, some of the immune defects caused by prenatal zinc deficiency may even persist into subsequent generations (Table 2). In mice, suppressed IgM concentration and impaired lymphocyte proliferation have been 
observed in second and third generation offspring (Beach et al. 1982b). The mechanisms responsible for this persistency are still unknown but changes in methylation patterns of immunoregulatory genes and other putative epigenetic effects have been proposed (Keen \& Gershwin, 1990). It should be noted that the immune defects mentioned above have also been observed in the offsprings of only marginally zinc deficient mice. However, there definitely arises a need for further studies to determine the significance of these observations in humans since data about the consequences of gestational zinc deficiency for the immune response of the newborn are still completely lacking. Prenatal zinc deficiency might have an important effect on child immunity as observed in animal studies. Hypogammaglobulinaemia together with altered antibody repertoire and decreased T-cell proliferation in response to T-cell dependent antigens may lead to impaired success of vaccination in the infant which again may have important consequences for the health status of the population. In humans, immunological defects might possibly also be seen in subsequent generations as suggested by animal studies and may be irreversible (Beach et al. 1983).

\section{Immunoregulatory effects of zinc}

Zinc supplementation in humans has been shown to reverse nearly all the defects as seen in zinc deficiency. Reversal of thymic involution, most probably caused by inhibition of apoptosis, and, as a consequence, increased thymulin levels have been observed (Mocchegiani et al. 1995). This facilitates normal T-cell development and helper cell function. Impaired functions of macrophages, neutrophils, NK cells, and B-cells are also restored. Interestingly, zinc administration can not only reverse impaired immune function but it can even enhance normal immune response (Crea et al. 1990; Wellinghausen et al. 1997a). In fact, zinc is the simplest mitogen known, being able to stimulate peripheral blood mononuclear cells. Zinc can directly induce cytokines like interleukin 1 and 6 and tumor necrosis factor alpha in human monocytes. Zinc-stimulated monocytes can then stimulate T-cells (Kirchner \& Rühl, 1970; Salas \& Kirchner, 1987; Driessen et al. 1994). Zinc is, it seems, involved in nearly all levels of the immune response.

\section{Zinc supplementation in humans}

In the recent past, several large community-based supplementation trials involving groups at an increased risk of zinc deficiency have been conducted. For instance, in double-blind, randomized controlled trials, zinc supplementation has led to a reduction in the incidence and prevalence of diarrheal disease and respiratory tract infections in children of low socioeconomic status (Sazawal et al. 1995; Black, 1998). Zinc supplementation has not only been evaluated as a therapeutical measure but it has also proven useful to prevent diarrhea and malaria morbidity when administered prophylactically (Black, 1998). Supplementation trials on pregnant women, a population at great risk of zinc deficiency, are controversial. On the one hand, improved fetal neurobehavioral development, greater fetal birth weight and reduced preterm delivery and placental abruption have been described (Merialdi et al. 1999; Goldenberg et al. 1995; Jameson, 1993) whereas, on the other hand, studies showing no beneficial effect on, for example, birth size are also available (Caulfield et al. 1999b). Surprisingly, studies investigating immunological effects of a zinc supplementation on pregnant women are very limited. There has been reported a lowered rate of spontaneous abortions after gestational zinc supplementation (Jameson 1993; Caulfield et al. 1998) but studies directly addressing immunological mechanisms are completely lacking.

Despite the potential advantages of zinc substitution, the administration of zinc should optimally be assessed on the individual's particular requirements and controlled by plasma zinc level because depressed immune function has been reported with high dose zinc therapy. Of course, such an individually adapted supplementation approach is neither possible nor even desirable in the interest of public health but may be applicable in individual cases. At zinc dosages of $100-300 \mathrm{mg} / \mathrm{day}$, i.e. ten times the daily requirements, diminished lymphocyte proliferation, neutrophil chemotaxis and phagocytosis have been reported in humans (Chandra, 1984). Interestingly, monocytes and T-cells show a different susceptibility to high zinc dosages. While monocytes are stimulated by and can tolerate quite high zinc concentrations, T-cell function is impaired at much lower zinc levels which can be achieved by zinc supplementation (Wellinghausen et al. 1997b). This explains why immunosuppression by high zinc dosages mainly affects T-cell function. However, even at dosages below $100 \mathrm{mg} /$ day effects on the homoeostasis of other micronutrients, such as a depressed copper level and an altered metabolism of vitamin A, may be observed (Fischer et al. 1984; Vallee \& Falchuk, 1993; Christian \& West, 1998).

As mentioned earlier, it is very difficult to determine a safe upper limit of zinc administration. The WHO established safe upper limits of daily zinc intake, i.e. up to $13 \mathrm{mg}$ for infants up to one year, $23 \mathrm{mg}$ for children aged 1-6 years, 32-34 mg for adolescents, and up to $50 \mathrm{mg}$ for adults (Walsh et al. 1994). However, these recommendations are based mainly on short-term trials and may not take into account the possible negative effects of long-term zinc supplementation. Some of the authors agree in considering a daily dosage of $50 \mathrm{mg}$ zinc as safe (Favier \& Favier, 1990) Fischer et al. observed depression of copper-zinc superoxide dismutase in normal adults after only 6 weeks of $50 \mathrm{mg}$ daily zinc supplementation (Fischer et al. 1984). Others recommend a total intake of only $20 \mathrm{mg}$ zinc daily (Mertz, 1995). In his toxicity assessment of zinc supplementation, which considered possible negative interactions between zinc and other trace elements as well as risks of long-term supplementation, Sandstead calculated a daily intake of only $9 \mathrm{mg}$ zinc for $60-\mathrm{kg}$ adults as the upper limit without negative side-effects (Sandstead, 1995).

In the light of the problematic nature of an adequate zinc dosage the 1989 RDA committee noted that chronic ingestion of zinc supplements at a level exceeding $15 \mathrm{mg}$ per day is not recommended without medical supervision 
(National Research Council, 1989). However, according to the Third National Health and Nutrition Examination Survey about $40 \%$ of pregnant and lactating females in the US take daily zinc supplements of $>15 \mathrm{mg}$ (Briefel et al. 2000). It is possible that the current RDA of $15 \mathrm{mg}$ per day for pregnant and lactating women is no longer applicable and should be lowered, following the example of Canada and the United Kingdom. However, before fixing a limit of safe zinc intake and especially before recommending an increased intake in zinc supplements it is necessary to carry out laboratory studies and field trials addressing the dose-dependent specific effects of zinc on immunity and general pathophysiology.

\section{Conclusions}

Due to its great significance not only for the adult but especially for the developing immune system, a balanced zinc status is particularly important during pregnancy. As discussed in this article, gestational zinc deficiency has immense consequences for the affected women as well as for the developing fetus and infant. Perhaps the most remarkable effect of gestational zinc deficiency is the fact that some immunodeficiencies can persist in subsequent generations, as has been demonstrated in mice. This suggests that gestational zinc deficiency may have epigenetic effects. Given the potential short- and longterm immunological consequences of even moderate zinc deficiency, a better understanding of its effect on public health is clearly needed. Further knowledge of how zinc affects the immune system, particularly during pregnancy, will depend on a closer integration of modern immunology, cellular and molecular biology and nutritional sciences into field-based studies and intervention programmes. Large community-based zinc supplementation trials in certain groups at an increased risk of zinc deficiency, in particular in pregnant women, will be essential. Although immunological data on the effects of zinc supplementation during pregnancy are still lacking, a reduced risk of abortion in zinc-supplemented pregnant women may suggest an 'immunological' benefit of zinc supplementation. But before starting large supplementation trials in women the fundamental question of the adequate and safe zinc dosage, when taken over a prolonged period of time, has to be answered. Nutritional surveys like those conducted in the US (Briefel et al. 2000) may contribute relevant information to this topic. Finally, clinical and immunological data will broaden the horizon of our knowledge about the immunobiology of zinc and make it available for the benefit of the whole population.

\section{References}

Bach JF (1981) The multi-faceted zinc dependency of the immune system. Immunology Today 4, 225-227.

Bedwal RS \& Bahuguna A (1994) Zinc, copper and selenium in reproduction. Experientia 50, 626-640.

Beach RS, Gershwin ME \& Hurley LS (1982a) Reversibility of development retardation following murine fetal zinc deprivation. Journal of Nutrition 112, 1169-1181.
Beach RS, Gershwin ME \& Hurley LS (1982b) Gestational zinc deprivation in mice: persistence of immunodeficiency for three generations. Science 218, 469-471.

Beach RS, Gershwin ME \& Hurley LS (1983) Persistent immunological consequences of gestational zinc deprivation. American Journal of Clinical Nutrition 38, 579-590.

Black RE (1998) Therapeutic and preventive effects of zinc on serious childhood infectious diseases in developing countries. American Journal of Clinical Nutrition 68, 476S-479S.

Briefel RR, Bialostosky K, Kennedy-Stephenson J, McDowell MA, Ervin RB \& Wright JD (2000) Zinc intake of the US population: findings from the third National Health and Nutrition Survey, 1988-1994. Journal of Nutrition 130, 1367S-1373S.

Caulfield LE, Zavaleta N, Shankar AH \& Merialdi M (1998) Potential contribution of maternal zinc supplementation during pregnancy to maternal and child survival. American Journal of Clinical Nutrition 68, 499S-508S.

Caulfield LE, Zavaleta N \& Figueroa A (1999a) Adding zinc to prenatal iron and folate supplements improves maternal and neonatal zinc status in a Peruvian population. American Journal of Clinical Nutrition 69, 1257-1263.

Caulfield LE, Zavaleta N, Figueroa A \& Leon Z (1999b) Maternal zinc supplementation does not affect size at birth or pregnancy duration in Peru. Journal of Nutrition 129, 1563-1568.

Chandra K (1984) Excessive intake of zinc impairs immune response. Journal of the American Medical Association 252, 1443-1446.

Christian P \& West KP (1998) Interactions bewteen zinc and vitamin A: an update. American Journal of Clinical Nutrition 68, 435S-441S

Crea A, Guérin V, Ortega F \& Hartemann P (1990) Zinc et systeme immunitaire. Annales Medicine Interne 141, 447-451.

Dowd PS, Kelleher J \& Guillou PJ (1986) T-lymphocyte subsets and interleukin-2 production in zinc-deficient rats. British Journal of Nutrition 55, 59-69.

Driessen C, Hirv K, Rink L \& Kirchner H (1994) Induction of cytokines by zinc in human peripheral blood mononuclear cells and separated monocytes. Lymphokine and Cytokine Research 13, 15-20.

Favier A \& Favier M (1990) Conséquences des déficits en zinc durant la grossesse pour la mère et le nouveau-né. Revue francaise de Gynécologie et Obstétricie 85, 13-27.

Favier AE (1992) The role of zinc in reproduction. Biological Trace Element Research 32, 363-382.

Fischer P, Giroux A \& L'Abbe M (1984) Effect of zinc supplements on copper status in adult men. American Journal of Clinical Nutrition 40, 743-746.

Goldenberg RL, Tamura T, Neggers Y, Copper RL, Johnston KE, DuBard MB \& Hauth JC (1995) The effect of zinc supplementation on pregnancy outcome. Journal of the American Medical Association 274, 463-468.

Good RA (1981) Nutrition and immunity. Journal of Clinical Immunology 1, 3-11.

Hadden JW (1992) Thymic endocrinology. International Journal of Immunopharmacology 14, 345-352.

Jameson S (1993) Zinc status in pregnancy: the effect of zinc therapy on perinatal mortality, prematurity, and placental ablation. Annals of the New York Academy of Science 678, $178-192$.

Keen CL \& Gershwin ME (1990) Zinc deficiency and immune function. Annual Reviews of Nutrition 10, 415-431.

Kirchner H \& Rühl H (1970) Stimulation of human peripheral lymphocytes by $\mathrm{Zn}^{2+}$ in vitro. Experimental Cell Research 61, 229-230.

Kruse-Jarres JD (1989) The significance of zinc for humoral and cellular immunity. Journal of Trace Elements and Electrolytes in Health and Disease 3, 1-8. 
Merialdi M, Caulfield LE, Zavaleta N, Figueroa A \& DiPietro JA (1999) Adding zinc to prenatal iron and folate tablets improves fetal neurobehavioral development. American Journal of Obstetrics and Gynecology 180, 483-490.

Mertz W (1995) Risk assessment of essential trace elements: new approaches to assessing recommended dietary allowances and safety limits. Nutrition Review 53, 179-185.

Mocchegiani E, Santarelli L, Muzziolo M \& Fabris N (1995) Reversibility of the thymic involution and of age-related peripheral immune dysfunction by zinc supplementation in old mice. International Journal of Immunopharmacology 17, $703-718$.

National Research Council (1989) US Recommended Daily Allowances 10th edition. Washington, DC: National Academy Press.

Neldner KH \& Hambidge KM (1975) Zinc therapy in acrodermatitis enteropathica. New England Journal of Medicine 292, 879-882.

Prasad AS \& Oberleas BE (1970) Binding of zinc to amino acids and serum proteins in vitro. Journal of Laboratory and Clinical Medicine 76, 416-425.

Prasad AS (1991) Discovery of human zinc deficiency and studies in an experimental human model. American Journal of Clinical Nutrition 53, 403-412.

Prasad AS (1995) Zinc: an overview. Nutrition 11, 93-99.

Salas M \& Kirchner H (1987) Induction of interferon- $\gamma$ in human leukocyte cultures stimulated by $\mathrm{Zn}^{2+}$. Clinical Immunology and Immunopathology 45, 139-142.
Sandstead HH (1995) Requirements and toxicity of essential trace elements illustrated by zinc and copper. American Journal of Clinical Nutrition 61, 621S-624S

Sazawal S, Black RE, Bhan MK, Bhandari N, Sinha A \& Jalla S (1995) Zinc supplementation in young children with acute diarrhea in India. New England Journal of Medicine 333, 839-844.

Shankar AH \& Prasad AS (1998) Zinc and immune function: the biological basis of altered resistance to infection. American Journal of Clinical Nutrition 68, 447S-463S.

Valdes-Ramos R (1992) Zinc: a perinatal point of view. Progress in Food and Nutrition Science 16, 279-306.

Vallee BL \& Falchuk KH (1993) The biochemical basis of zinc physiology. Physiological Reviews 73, 79-118.

Vruwink KG, Hurley LS, Gershwin ME \& Keen CL (1988) Gestational zinc deficiency amplifies the regulation of metallothionein induction in adult mice. Proceedings of the Society for Experimental Biology and Medicine 188, 30-34.

Walsh CT, Sandstead HH, Prasad AS, Newberne PM \& Fraker PJ (1994) Zinc: health effects and research priorities for the 1990s. Environmental and health perspectives 102, 5-46.

Wellinghausen N, Kirchner H \& Rink L (1997a) The immunobiology of zinc. Immunology Today 18, 519-521.

Wellinghausen N, Martin M \& Rink L (1997b) Zinc inhibits interleukin 1-dependent T-cell stimulation. European Journal of Immunology 27, 2529-2535. 